\title{
POST-OPERATIVE FLUID COMPLICATIONS
}

\author{
By B. J. Houghton, M.B., B.S. \\ Lately Clinical Research Fellow, Surgical Unit, St. Mary's Hospital
}

Changes in the water and electrolyte content of the body tissues after surgical operations occur as the result of two factors. On the one hand, there are the various changes consequent upon altered intake and excessive loss of these materials, as, for example, in disorders affecting the gastrointestinal tract and with haemorrhage, and on the other hand, there are several less specific but equally important changes which occur as the physiological response to trauma. The latter, which were first observed in detail by Cuthbertson (1930) and have been studied minutely in recent years (Moore and Ball, 1952; Wilkinson et al., 1950, and others), are reviewed elsewhere in this issue and will only be mentioned here in relation to the genesis and treatment of individual fluid and electrolyte disturbances. It is often argued that patients survived major surgical operations and illnesses long before these newer ideas were conceived, but, of course, the same is true for antibiotics and modern anaesthesia, the value of which no one would deny, and prevention of a complication still remains better than its cure. Mortality figures can be improved by such means, as they were amongst cases of infantile diarrhoea when potassium supplements were first tried (Darrow, 1946). It is probably no exaggeration to say that many patients who in the past succumbed to the after-effects of an operation did so not from ' toxaemia' or ' shock' but from a then unrecognized biochemical complication. This, then, is the justification for yet another review of our present knowledge in this field, which is the concern of clinician, pathologist and physiologist alike.

\section{General Considerations}

Claud Bernard emphasized the importance to living organisms of maintenance of the constancy of the 'milieu interieur,' and during the course of evolution an elaborate system of homeostatic mechanisms has developed by which this is achieved. Consequently, we find in man a remarkable constancy in the water and electrolyte content, acid-base balance and volume of the body fluids, and it is clearly necessary to have some familiarity with the factors involved in order to understand the nature of the disorders seen after he has been submitted to a major surgical operation. Although the existence of 'osmoreceptors' has been clearly indicated following the pioneer work of Verney (1947), there is, as yet, little known about the mechanism of control of the overall fluid volume, although a 'volume receptor' was postulated in 1948 by Peters and Borst. In the normal course of events it appears that the body maintains the $\mathrm{pH}$ and osmolarity (osmotic solute content) of the fluids bathing the cells with more vigour than the total volume, and this is, perhaps, not surprising in view of the changes in the latter that occur with intestinal absorption after feeding. However, there are clinical situations, for example, severe sodium depletion and haemorrhage, in which maintenance of constancy of volume eventually takes precedence over osmolarity and acid-base balance control, and similar observations have been made under experimental conditions (McCance, 1936).

The disturbances of fluid balance that occur in surgical conditions can be grouped in several ways, their essential nature having been elucidated and described by a large number of workers (Gamble, Hartmann, Darrow, Coller and Maddock, Cuthbertson, Marriott, McCance, Elkinton and many others). In the first place we must consider the disorders leading to alteration of total fluid and electrolyte content, and, therefore, changes of osmolarity. Later it will be necessary to review the changes in acid-base balance and the special role of potassium, and to consider the complications due to disorders of cardio-respiratory, renal and suprarenal function in altering the response of the organism. The final and major object of this discussion must be to outline methods of avoiding these hazards in routine surgical practice.

\section{Disturbances of the Total Body Fluid and Electrolyte Content}

These may consist of a deficiency or excess of water or electrolytes, or both, and a mixture of these conditions is commonly encountered. 


\section{The Depletion Syndromes}

The clinical state generally described as 'dehydration' may consist either of loss of water by itself (the true meaning of the term) or loss of water and variable amounts of sodium salts. In view of the marked clinical differences between these states it is probably best to avoid the term dehydration altogether and to use Marriott's classification, as follows here.

(i) Water Depletion. Loss of water occurs in two ways: namely, by extrarenal routes as vapour in the expired air, insensible skin loss, sweat, and water in the faeces, and by renal excretion as urine. The insensible skin loss and respiratory water loss was estimated by Dubois in 1927, who found it to be an average of $0.5 \mathrm{~g}$. of water per kg. body weight per hour in adults, and this has been confirmed by others. Thus for a $70-\mathrm{kg}$. man the total loss is approximately $840 \mathrm{ml}$. per 24 hours, and this is increased in febrile conditions and elevation of the metabolic rate. Faecal loss of water clearly varies considerably, depending on many factors, but allowing an average of $150 \mathrm{ml}$. per 24 hours, and not less than $500 \mathrm{ml}$. of urine over the same period, the minimum obligatory loss of water in health is generally accepted as approximately $1,500 \mathrm{ml}$. per 24 hours. Hence if the available water is less than this volume, or there is excessive loss from one or more of these routes, water depletion is bound to occur.

Intake of water may be deficient due to coma or inadequate parenteral administration where the oral route is contraindicated, or it may be relatively insufficient compared with the intake of excretable solutes such as electrolytes and, in the case of the diabetic patient, glucose.

Excessive loss may be from the skin in fever or a raised atmospheric temperature, hyperventilation, and polyuria as seen, for example, in renal insufficiency, glycosuria and diábetes insipidus. The latter, of course, has a particular surgical importance in relation to hypophysectomy, as nowadays practised for some forms of advanced malignant disease.

The cardinal feature of water depletion is thirst, and it is this symptom which generally guides the clinician in assessing his patient's water requirements. Clinical signs are relatively slight at first, but as the condition becomes more severe and the body is depleted of 2 litres or more of water, dryness of the tongue and mucous membranes is apparent, together with the production of only small volumes of urine with a high specific gravity. A high potassium concentration may be found in the urine, and this is a reflection of the transfer of water and potassium from the reservoir of cell fluid, the 'toxic' potassium being hastily excreted. In severe cases restlessness, a per- sonality change, impaired mental function leadingi to stupor, and a marked rise in the plasma sodium? concentration (and other evidence of haemo- $\vec{D}$ concentration) may occur. If treatment is nof commenced immediately, hyperpyrexia and death. ensue.

Administration of water in adequate quantities? produces a complete regression of symptoms and흠. signs, and the restoration of a normal urine output. $\frac{\infty}{\widetilde{\alpha}}$

(ii) Sodium Depletion (Salt Depletion). The average normal diet for man contains 80 to 150 w mEq. of sodium per 24 hours. Apart from a $\vec{\circ}$ small amount ( 3 to $5 \mathrm{mEq}$.) which is lost in the skin secretions and also in the faeces ( 3 to $5 \mathrm{mEq}$.) $\vec{\omega}$ an equivalent amount is lost in the urine. Ino health the body can maintain homeostasis on a 3 fraction of this intake, and that this is possible is due to an efficient sodium conservation mechanism $\omega$ in the kidney, which is apparently mainly undero the control of the hormones of the adrenal cortex. O In renal disease such as chronic pyelonephritise and chronic glomerulonephritis, and in adrenalo cortical insufficiency (Addison's disease) excessive and uncontrolled sodium losses in the urine mayo occur, and therefore it is important to remember this effect when such a patient has to have an $\frac{\mathbb{D}}{3}$ operation, for in contrast to the normal person who excretes very little sodium in the urine in the first four or five days, as part of the physiologialo response to trauma, these patients may continese. to lose large amounts.

As apart from these special conditions a deficient sodium intake is compensated by a greatly reduced $\bar{O}$ output of sodium in the urine, it follows that the majority of cases of clinical sodium depletion $\stackrel{\perp}{\perp}$ occur as the result of excessive extrarenal losses $\overrightarrow{\overrightarrow{\vec{P}}}$ and mainly, therefore, by vomiting, diarrhoea, or 3 pooling of fluid in the gastro-intestinal tract or serous cavities. If the patient's fluid losses areㅁ. repaired by water alone, or, at most, by sodium-containing solutions of low concentration, then a 3 . state of sodium depletion (salt depletion) may ${ }_{3}^{\circ}$ occur whilst the total water content of the body is normal. As might be expected, the plasmao sodium, chloride and bicarbonate concentrations are found to be low (the sodium may be as low? as $120 \mathrm{mEq}$. per litre) and, in fact, the volume of $>$ the extracellular compartment is also reduced. A relatively high haematocrit is found as evidencen of haemoconcentration.

Reduction in the extracellular fluid volume $N$ causes lassitude and weakness, signs of loss of $\omega$ skin elasticity and tissue turgor, reduced blood pressure and tachycardia, with a tendency too fainting when sitting up. Oliguria and a rise in blood urea follow, and if the condition is not ${ }^{+}$ treated immediately, death results from oligaemia $\frac{T}{0}$ 
and uraemia ('pre-renal' or ' extra-renal' uraemia).

(iii) Mixed Water and Sodium Depletion. In fact these pure depletion syndromes described are relatively uncommon, and the great majority of cases which are clinically 'dehydrated' are in fact suffering from combined water and salt depletion in varying proportions. The clinical features are mainly those of sodium depletion although the patient may complain of thirst, and the blood analysis findings vary with the nature of the predominant deficits. In all cases a raised haematocrit will be found, unless, of course, the patient was grossly anaemic before his illness or lost excessive blood during his operation.

The treatment of sodium depletion is adequate replacement with this ion in the form of sodium chloride. In most cases this will be given in isotonic solution (normal saline) because of the accompanying deficiency of water, but in cases of pure sodium depletion with a normal body water content, administration of a hypertonic solution will be desirable. The quantities and principles of calculation will be considered later.

\section{The Syndromes of Water and Electrolyte Overloading}

Much has been said and written in the past by clinicians about the dangers of excessive intravenous infusions, but all too commonly the resulting condition is described loosely as 'waterlogging' or 'overhydration' without stating which components are in excess. However, the effects of excess water or sodium, or both, give just as definite clinical disorders as do the corresponding depletions, and should always be considered from this standpoint.

(i) Clinical Effects of Excess of Water. It is difficult to produce symptoms in a normal healthy person by excessive administration of water, whether by oral or parenteral routes, unless the normal diuretic response is artificially inhibited by injection of posterior pituitary extract. However, in the early post-operative period it is all too easy, owing to the operation of an antidiuretic mechanism which is thought to be mediated via the supraoptico-hypophyseal mechanism. Apart from the obvious risk of too large an intravenous infusion of dextrose-in-water solutions, the danger of rectally administered water is insufficiently realized, and this is due to a widely-held but erroneous belief that the body only absorbs the required amount of water from the bowel. Unfortunately, the behaviour of the bowel in this respect is extremely variable in different subjects and completely unpredictable, and some of the most severe cases of water intoxication have been seen in these circumstances (de Takats, r93 I).
Excess water is distributed throughout all the body fluid compartments, diluting them to an $\varrho$ equivalent extent in terms of osmotic strength $\frac{3}{1}$ (Wynn, 1955). In the normal way, therefore, approximately two-thirds of the added water accumulates inside the cells. The extent of $\underset{\vec{S}}{\vec{*}}$ dilution of the body fluids is reflected in a lowered plasma sodium, chloride and bicarbonate, and $\bar{\square}$ the symptoms generally appear when the sodium is below $120 \mathrm{mEq}$. per litre. Initial symptoms are $\overparen{\alpha}$ lassitude, mental depression and confusion, nausea and vomiting. Later, restlessness, rapid respirations, spontaneous muscular twitching and drowsiness appear and, if untreated, the patient slips into coma and may have generalized convulsions. The reflexes may be exaggerated.

Treatment depends on whether the patient is capable of having a spontaneous diuresis, but $\underset{\omega}{\omega}$ assuming this is not possible, these being the $\omega$ circumstances in which it usually occurs, then it $\%$ is necessary to infuse hypertonic sodium chloride intravenously at a slow rate.

(ii) Clinical Effects of Excess of Water and Sodium. This is the commonest form of fluid overloading and results when isotonic saline and dextrose-saline solutions are given in excess of the patient's maximum output. It is therefore like to occur chiefly during the first five post-operative days or in cases of cardiac or renal failure. The $\overrightarrow{0}$ excess of sodium salts is almost entirely confine 8 . to the extracellular fluid compartment, which thereby expanded, causing haemodilution and oedema with the appropriate risk of pulmonary oedema. Unless there is a relative excess of water compared with the extra sodium, the patient's plasma sodium concentration will be normal. Treatment is, of course, to stop further sodium administration, restrict water intake to that necessary to cover the obligatory losses, and, if necessary, to adopt the measures for the treatment of congestive cardiac failure.

(iii) Clinical Effects of Excess of Sodium Salts Alone. This situation is relatively uncommon except where an unconscious patient has had his entire daily fluid requirements supplied in the form of isotonic saline and is unable to express $\frac{9}{5}$ his thirst. Insensible water vapour loss con- $D$ tinues to deprive him of about 800 to $1,000 \mathrm{ml}$. of water each 24 hours, and although oliguria $N$ develops, with a high electrolyte output, the inevitable result is that the body fluids become $N$ hypertonic. The clinical condition is essentially $\underset{\omega}{N}$ the same as that of water depletion, except that $\widetilde{O}$ when the patient is given the extra water that he 0 needs, slight oedema may appear temporarily until $\overparen{\varnothing}$ excretion of the excess sodium (and water) is? effected. 


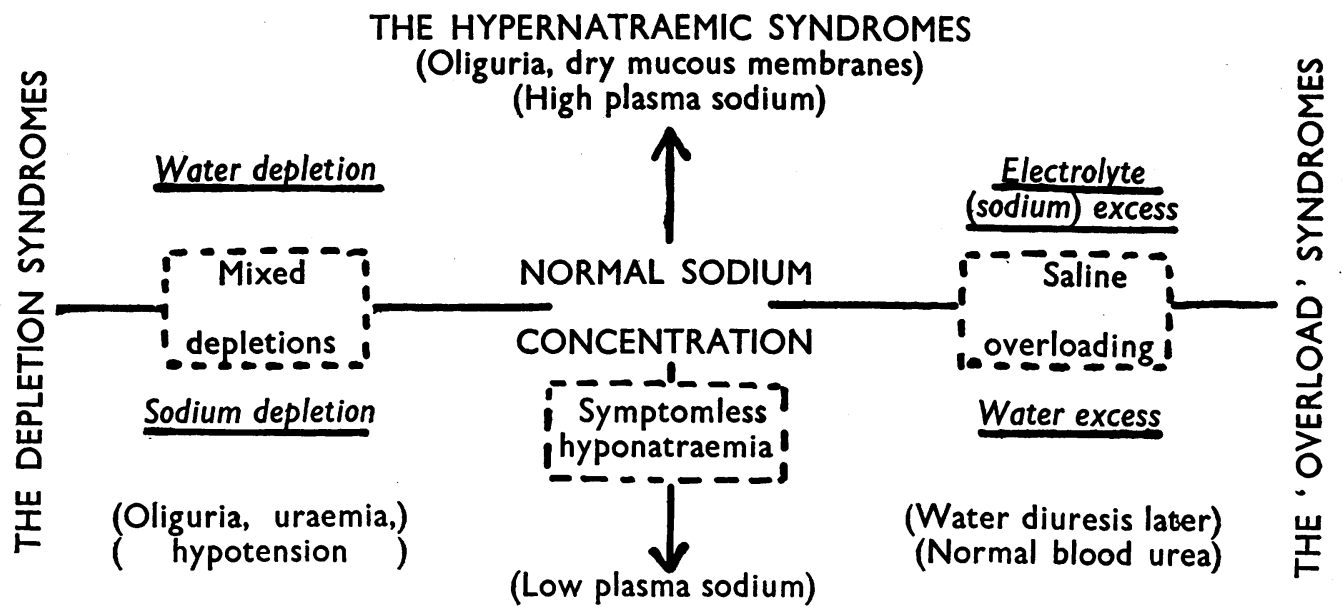

\section{THE HYPONATRAEMIC (HYPOTONICITY) SYNDROMES}

FIG. 1.-The 'tetrad' of osmotic syndromes.

\section{Chronic Adjustments}

The various disorders of osmolarity which have been described can be represented as a tetrad (Fig. I), showing the differential diagnosis and similarities of the low and high osmolarity states, depletions and overloading syndromes. There is one other condition which should be mentioned in connection with the low osmolarity states, and that is one which was observed by Coller and Maddock in I940. It is now variously described as asymptomatic hyponatraemia, symptomless hypotonicity or chronic low salt syndrome, and it is found in many chronic wasting illnesses, such as tuberculosis, carcinomatosis, post-operative sepsis, and fistulas. It is characterized by a low plasma sodium, which cannot be raised by administering additional sodium in the diet, and, surprisingly, the absence of the symptoms of acute salt depletion. It is probably related to chronic potassium and protein depletion and disappears if and when the patient recovers from his illness. Recently, however, it has been suggested that it represents a chronic excess of water and that it can be improved by the administration of cortisone, which facilitates a spontaneous diuresis. Thus it might be related to chronic suprarenal hypoactivity.

\section{Disturbances of Potassium Balance}

The clinical importance of potassium has mainly been recognized since Darrow (1946) described the beneficial effects of its administration in cases of infantile diarrhoea. It is, of course, the predominant intracellular cation and is only present in the blood and extracellular fluid in low and carefully limited concentrations, where it appears to be functionally related to nerve and muscle excitability. The exact concentration is only of limited significance in relation to the total body content, for raised plasma potassium levels may be found in the presence of marked potassium depletion, and low levels in normal persons, but it appears to be related to the general cell metabolism according to whether the cells are retaining or shedding it. Generally, however, in surgical patients constant low plasma concentrations are a feature of overall potassium deficiency, and elevated levels are found in states of renal failure.

\section{Potassium Deficiency}

As excretion of potassium continues in all circumstances except anuria, depletion of the body content can occur just as a result of deficient intake, in contrast to sodium. Recent work, however, has demonstrated that in conditions of persistent low intake, the potassium excretion may be reduced considerably below normal.

Urinary loss of potassium is increased in water depletion, alkalosis or following rapid intravenous infusions of isotonic saline or dextrose solutions, and large quantities may be lost in gastro-intestinal secretions. (The accompanying table shows the average composition of various gastro-intestinal fluids.) Evidence is accumulating (Darrow et al., 1948; Darrow and Pratt, 1950; Cooke et al., 1952; and others) that the lost intracellular potassium is replaced in part by sodium and hydrogen ions, and that this results in an extracellular alkalosis. Another form of loss, in direct propor- 
tion to nitrogen loss, occurs as the result of starvation and tissue catabolism following injury, and in these circumstances alkalosis is uncommon.

The most useful evidence in diagnosing potassium depletion is a long history of loss of secretions. The clinical features are variable but essentially consist of weakness, lassitude, apathy, slurred slow speech, drowsiness and personality changes. In addition, post-operative ileus may fail to recover, urinary incontinence may occur and the reflexes may be weak. The blood pressure is often low, and E.C.G. changes consisting of reduction in voltage, diminution or inversion of the $\mathrm{P}$ waves, $\mathrm{S}-\mathrm{T}$ depression and inversion of $T$ waves, prolongation of the $Q-T c$ intervals and the appearance of $U$ waves are described, but are not necessarily present.

Treatment consists of replacement with potassium salts, usually the chloride, which should preferably be given by mouth, but may have to be administered intravenously when oral feeding is impracticable.

\section{Potassium Excess}

It is not possible to elevate the plasma potassium in healthy persons to dangerous levels by excessive administration of potassium salts, and this is because of an efficient excretory mechanism in the kidneys. It follows that cases of potassium intoxication post-operatively occur as the result of renal failure or gross functional oliguria. There are few clinical signs except for a slow, irregular heart beat, and this is commonly anticipated by E.C.G. changes consisting of peaked $T$ waves, prolonged PR interval and widened QRS complexes, when the potassium concentration exceeds $7 \mathrm{mEq}$. per litre.

\section{Acid-base Balance Disorders}

In the normal person regulation of acid-base equilibrium is maintained by the kidneys and, to a lesser extent, by the respiratory system, and disease of either may lead to profound biochemical derangement. The acidosis consequent upon uncontrolled diabetes mellitus and upon renal failure is well known, as is the alkalosis found in patients vomiting from pyloric stenosis, but the acidosis and alkalosis found in respiratory disorders are less familiar to the general surgeon than to his physician colleagues. Essentially, the acid-base disturbances can be grouped into those of metabolic origin and those due to respiratory disorders, and each will be mentioned separately.

\section{Metabolic Acidosis}

The classical example of this condition is, of course, uncontrolled diabetes mellitus, in which acid ketone bodies accumulate in the blood and extracellular fluid as a result of deranged carbohydrate metabolism. The hydrogen ions from these acids neutralize some of the plasma bicarbonate producing a fall in its concentration (reduced ' alkali reserve' or carbon dioxide combining power) and a fall in the blood $\mathrm{pH}$. With the low bicarbonate the plasma electrolyte pattern also reflects the acidosis in that the total of $\mathrm{Cl}+\mathrm{HCO}_{3}$, which normally is about 8 to $12 \mathrm{mEq}$; per litre less than the sodium level, is reduced; indicating the presence of the ketone anions. Renal failure gives a similar set of changes, the unusual anions in this case being excess of phosphate and sulphate, although there is, of course, an accompanying rise in the blood urea. Also, as mentioned previously, sodium depletion can be the cause of this extrarenal uraemia and metabolic acidosis. It is obviously of great importance to watch for this state of affairs in surgical patients. as a slight degree of metabolic acidosis is very commonly found after any major operation, with the attendant low calorie intake and ketosis in the immediately succeeding days.

A metabolic hyperchloraemic acidosis due to the accumulation of chloride ions may occur in nephrotic patients, in cardiac cases after ammonium chloride administration and following transplantation of the ureters into the lower bowel.

Clinical features are those of the causative condition, but when acidosis is advanced the patient becomes disproportionately ill, has a low blood pressure and may have deep rapid respirations. The latter are due to the reduced plasma bicarbonate (alkali reserve) which is unable to buffer the accumulating carbonic acid in the tissue fluids and blood, and as the result the respiratory centre is stimulated. Remembering that at the normal pH of blood, 7.4, the proportion $\frac{\mathrm{BHCO}_{3}}{\mathrm{H}_{2} \mathrm{CO}_{3}}=\frac{20}{\mathrm{I}^{\prime}}$ ? it is apparent that when the $\mathrm{BHCO}_{3}$ is lowered, as in metabolic acidosis, a corresponding reductión of carbon dioxide tension in the alveolar air by hyperventilation, and therefore the reduction of blood carbon dioxide tension and $\mathrm{H}_{2} \mathrm{CO}_{3}$ concentration, is necessary to facilitate the correction of the $\mathrm{pH}$ towards normal.

\section{Metabolic Alkalosis}

This may result from subtraction of acid, as in the vomiting due to pyloric obstruction, and from excessive administration of alkali as, for example, in ulcer patients treated continuously with alkaline preparations, and it is therefore important to the surgeon chiefly as a pre-operative condition which should be corrected before submitting the patient to a surgical procedure. When due to alkali ingestion the body attempts adjustment : by 
secreting an alkaline urine containing sodium and bicarbonate ions, but when the alkalosis is due to vomiting gastric juice the paradox of secretion of an acid urine is often found. This is due to active sodium retention consequent upon loss of extracellular fluid, continued small losses of potassium in the gastric'secretions and obligatory potassium loss in the urine, frequently resulting in an intracellular acidosis (Cooke et al., 1952). This biochemical complication is frequently found in patients vomiting post-operatively owing to a temporary pyloric or stomal block.

The alkalosis is characterized by irritability and mental depression, cyclical periods of shallow respiration, almost amounting to apnoea, and spontaneous tetany and myotatic irritability. The plasma bicarbonate is proportionately high (up to $60 \mathrm{mEq}$. per litre), the chloride correspondingly low, and the plasma sodium may be elevated as the result of excessive sodium intake or excess water loss in vomiting. It is now thought that potassium depletion plays a major part in the causation of the alkalosis and that treatment should be, primarily, its correction with potassium chloride.

\section{Respiratory Acidosis}

For the surgeon this is a relatively new hazard which has only come to the forefront since the introduction of relaxant drugs in anaesthesia. These are particularly dangerous to patients with chronic respiratory insufficiency, e.g. chronic bronchitis and emphysema, and more than ever before the patient is at the mercy of his attendants. If he is returned to the ward before the effect of the last injection of a relaxant agent has worn off, or has been countered by prostigmine, he may have a sufficiently reduced respiratory excursion toylead to a serious accumulation of carbon dioxide and a consequent respiratory acidosis. The persistence of a pink colour, due to vaso-dilatation, is a deceptive feature in a patient intoxicated with carbon dioxide and the diagnosis may be missed, for when the acidosis is severe the patient becomes deeply comatose, stops breathing and may develop signs suggestive of a cerebro-vascular accident, including papilloedema and a raised C.S.F. pressure.

Treatment consists of artificial ventilation with a respirator until the excess of carbon dioxide has been blown off and the patient regains consciousness.

Chronic respiratory acidosis as in bronchitic subjects is characterized by an accumulation of bicarbonate in the plasma to buffer the excess retained carbonic acid and, thus, restore the proportion $\frac{\mathrm{BHCO}_{3}}{\mathrm{H}_{2} \mathrm{CO}_{3}}$ and $\mathrm{pH}$ towards normal. It is essen- tially a medical condition, and it would be inappropriate to discuss it here except to say that such patients may be precipitated into the acute phase very easily by infections, any post-operative chest complication, or relaxant drugs.

\section{Respiratory Alkalosis}

This is the opposite to respiratory acidosis and occurs in anaesthetized patients who are overventilated by the anaesthetist, and in conditions where the respiratory centre is stimulated directly. The most familiar example of the latter seen by the surgeon is in hepatic coma, where hyperventilation is common and is due to primary stimulation of the respiratory centre by an unknown mechanism. In these circumstances excessive carbon dioxide is blown off with a resulting fall in the tension of the gas in the alveolar air and blood. A compensatory mechanism of metabolic acidosis and excretion of an alkaline urine subsequently result in a return of the $\mathrm{pH}$ towards normal and a fall in the plasma bicarbonate to levels below the normal range.

The conditions described above had a fourfold relationship to one another, as have the syndromes of disorders of osmolarity, and may be portrayed in a similar manner (Fig. 2).

\section{Shock}

The physiological and pathological responses to acute haemorrhage and shock are well known and so we can confine our attention here to the profound retention of sodium and water with resulting oliguria that occurs probably as the result of the operation of haemodynamic and hormonal factors.

The prolonged hypotension which may follow shock and oligaemia may, of course, lead to renal ischaemia and tubular necrosis, a serious complication which in spite of careful conservative management may be followed by a fatal issue. The principles of management in these circumstances are now firmly established along the lines suggested by Borst (1948), Bull, Joekes and Lowe (1949), and others, and essentially consist of $\frac{O}{3}$ restriction of water intake to $1,000 \mathrm{ml}$. plus the urine volume, limitation of electrolyte intake to that necessary to cover measured losses, and the $\frac{D}{0}$ provision of a high glucose intake to supply sufficient calories and reduce tissue catabolism. $N$ This regime can be given by intravenous or $N$ intragastric routes.

\section{The Influence of Co-existing Medical Conditions Chronic Cardiac Disorders}

The effect of cardiac insufficiency on the post-? operative salt and water balance is important to 


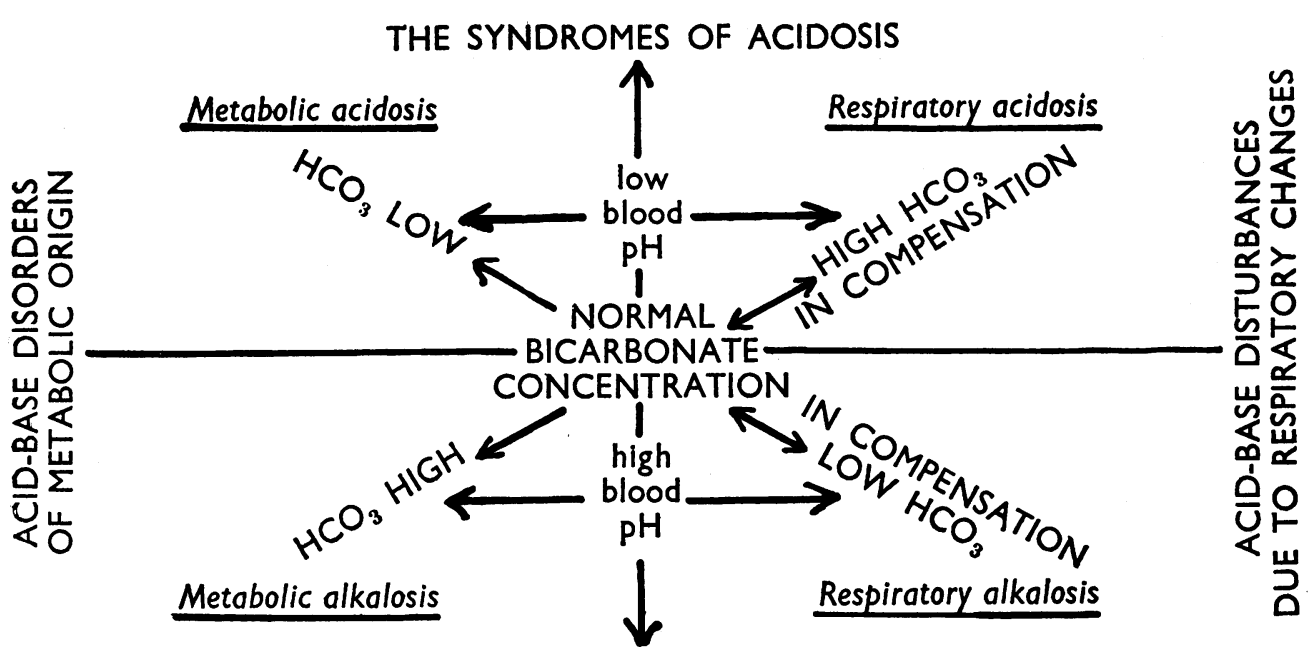

THE SYNDROMES OF ALKALOSIS

FIG. 2.-The 'tetrad' of acid-base balance syndromes.

remember when a patient with this condition needs to have an operation, and this is a frequent problem nowadays following the introduction of valvulotomy operations. A characteristic feature of the disorder is the tendency to retain sodium and water, and this, of course, is the basis for using a low salt diet in the medical control of cardiac oedema. It is clearly vital not to load such a patient with more sodium and water than he can excrete in the post-operative period, and it is equally important to treat any decompensation of cardiac function that may occur. In spite of the presence of oedema it is vital for these patients to be given the normal amount of water to cover their obligatory losses, or water depletion may be added to their troubles.

\section{Chronic Respiratory Disease}

This has already been discussed under acidbase disorders.

\section{Chronic Renal Disease}

This, of course, may take many forms and is in any case often a contraindication to any operation other than an urgent lifesaving procedure. The importance of recognizing urinary sodium loss in chronic renal disease has been mentioned, and the need to supply appropriately increased amounts of sodium salts in the post-operative period should be assessed on the basis of the 24-hour urinary sodium output.

In the nephrotic syndrome and some cases of chronic glomerular nephritis there is a marked sodium retention, and these cases must be managed with the same careful consideration as in the cardiac cases. Again the 24-hour urinary sodium output is a guide to the amounts that can be replaced, although any extra-renal losses must be fully covered.

\section{Diabetes Mellitus}

The fluid complications due to uncontrolled diabetes in the post-operative period are well known, and have been mentioned earlier. Essentially they consist of water, sodium and potassium depletion from polyuria with a superadded metabolic acidosis.

\section{Suprarenal Disorders}

The importance of recognizing Addison's disease and of the careful post-operative management with respect to adequate sodium replacement has also been discussed earlier, but should be emphasized again. Similar principles should govern the management of patients subjected to bilateral adrenalectomy, and in all these cases adequate substitution therapy with cortisone and desoxycorticosterone acetate is, of course, essential if an Addisonian crisis is to be avoided.

\section{Diseases Requiring Cortisone Therapy}

These are discussed elsewhere in this issue.

\section{Liver Disease}

Oliguria is a well-recognized feature in acute hepatic failure, but there are also important changes in chronic cirrhotic disease. Although the mechanisms are far from clearly understood, the cardinal features are formation of ascites and oedema, consequent upon a raised portal venous pressure and low plasma protein levels, and a tendency to retain sodium and water. The main- 
tenance of a low urinary sodium output in spite of a normal intake may be due to increased production or decreased inactivation of sodiumretaining hormones (Bongiovanni and Eisenmenger, 195I ; Goldman and Bassett, 1952), and increased amounts of an anti-diuretic substance (Hall et al., 1949; Sims, 1950) may account for the persistence of an oliguria in spite of variations in the intake. The low plasma protein levels undoubtedly assist the formation of peripheral oedema, but it may be that hormonal factors are involved in the initial retention of salt and water.

So far as the surgeon is concerned this means that after operations on cirrhotic patients the sodium and water intake must be very carefully supervised, as one would in the case of cardiac disease.

\section{Special Problems Associated with Surgery Hypothermia}

Artificial cooling of patients being subjected to major cardiovascular surgery and certain other operations is a relatively recent development and has brought some special biochemical problems of its own. Wynn (1954) has produced evidence that the metabolism of glucose is considerably reduced in hypothermia, and that the intravenous infusion of glucose or glucose-saline mixtures in these circumstances can lead to very high blood-sugar levels, even in excess of $1,000 \mathrm{mg}$. per $100 \mathrm{ml}$. Because the glucose is not taken up by cells under hypothermic conditions, the added glucose remains in the extracellular fluid and draws water out of the cells by osmotic forces, thereby rendering the cells relatively water-depleted. In order to avoid this complication it has been recommended that 2.5 per cent. glucose solutions, to halve the glucose load, or preferably plain saline solutions should be used.

Another complication is that citrate ions, from the anticoagulant in donor blood bottles, are less easily metabolized and may accumulate in the patient's blood. They have recently been blamed in cases of profound hypotension and cardiac arrest where decreased ionized calcium levels have been demonstrated (Bunker et al., 1955). Calcium salts have proved disappointing in the treatment and prevention of this condition.

Free potassium ions may be present in stored donor blood in relatively high concentrations (up to ro $\mathrm{mEq}$. per litre) and thus rapid and large bulk infusions in the hypothermic subject, whose glucose metabolism is depressed, may be dangerous. Freshly-drawn blood is safer.

\section{Ureterocolostomy}

This operation is now well established for cases where total cystectomy has to be performed for malignant disease and it has been shown to lead to an interesting biochemical complication, namely, that of hyperchloraemic acidosis. Many theories have been advanced to explain this condition, but recent work by Parsons et al. (1952) has shown that chloride is reabsorbed from the urine accumulating in the colon more quickly than is sodium. Patients affected by this condition may have nausea and vomiting, weakness and lassitude. Poor appetite leads to inadequate food intake and significant potassium depletion may occur. Relief is usually affected easily by continuous drainage of the lower bowel with an indwelling tube, and the biochemical changes regress. However, occasionally it may be necessary to administer potassium, and this is best given as potassium citrate mixture, $30 \mathrm{gr}$. three times a day (Wilkinson, 1954).

\section{Principles of Post-operative Fluid Management}

The first principle in preventing post-operative fluid complications is to have the patient in a correctly balanced state when he goes to operation, and however urgent the surgical procedure its success can always be made the more certain by spending a short while pre-operatively correcting blood loss or gross fluid depletion. Post-operao tively, the objectives are threefold: to correct los 8 of circulating blood volume with blood, plasma dextran, etc., as the situation demands; to cove $\bar{b}$. obligatory fluid and electrolyte losses; and to. replace losses incurred by vomiting and suchlike. It is with the latter two aspects that we are concerned here.

Fluid Requirements in Relation to the Stages of the Metabolic Response

(i) First 48 Hours. As mentioned earlier, in the first 24 to 48 hours after any major operation or general anaesthetic there is oliguria apparently due to primary water retention mediated by the pituitary antidiuretic mechanism. The small volume of urine secreted is characterized by a high specific gravity and high electrolyte content, but as the volume passed in the first 24 hours is seldom more than $600 \mathrm{ml}$., it is uncommon for the total electrolyte loss to be more than about $30 \mathrm{mEq}$. of sodium and $40 \mathrm{mEq}$. of potassium, and it is usually less. The insensible fluid loss is often high in the first 24 hours, covering the period in the operating theatre, and may amount to 900 to $1,200 \mathrm{ml}$. The sodium loss from the skin is about $5 \mathrm{mEq}$. Hence the overall obligatory fluid loss in the first 24 hours is about 1,500 to $1,800 \mathrm{ml}$., and the electrolyte loss relatively small. Of course, vomiting, diarrhoea, the drainage of fistulas, ascites and the like will add to the 
fluid and electrolyte loss, but this must be assessed and replaced appropriately to the individual case.

The obligatory losses in each 24 hours can be covered by 1,500 to $1,800 \mathrm{ml}$. of water and approximately $70 \mathrm{mEq}$. of sodium, given as sodium chloride, to replace sodium plus potassium. Thus, if the intravenous route is to be used, $500 \mathrm{ml}$. of normal saline may be given, and the rest of the fluid as dextrose in water solutions. In situations where intravenous therapy is not necessary, because the patient will be able to commence oral fluid feeding within 48 hours or so and electrolyte losses are small, as, for example, after uncomplicated partial gastrectomy, many surgeons favour the rectal route and 3 pints $(1,500 \mathrm{ml}$.) of water per 24 hours is a common and satisfactory prescription. Whenever possible, the patient should be allowed to take his fluids by mouth.

Clearly during this phase of primary water retention the risk of excessive administration is greatest, and water intoxication is a real danger when fluid intake is not carefully supervised.

(ii) Third to Sixth Post-operative Days. After the first 24 to 48 hours the oliguria passes off, but the characteristic finding at this stage is that the sodium content of the urine is low (average Io $\mathrm{mEq}$. per litre or less) and that the principal cation excreted is potassium. The amount of the latter which is lost seems to bear a rough direct relationship to the severity of the operation and metabolic response, and in some cases very large amounts (up to $150 \mathrm{mEq}$. per day) may be excreted in the urine. It is not surprising, therefore, that many patients are quite markedly depleted of potassium when they reach the sixth day of intravenous therapy unless some replacement of that ion has been prescribed, and it has been suggested, for example, with some good evidence, that delay in recovery from post-operative ileus is often due to potassium deficiency (Streeten and Ward-McQuaid, 1952; and others). Sodium should be adequately replaced if vomiting, diarrhoea and fistulas are producing sizeable losses, for otherwise there is a risk of salt depletion and, if a sudden increase in water intake occurs in these circumstances, superadded water intoxication.

Fluid prescriptions should aim to supply $\mathrm{I}, 800$ $\mathrm{ml}$. of water for obligatory losses (in addition some 100 to $200 \mathrm{ml}$. of water is formed in 24 hours from oxidation processes) and the appropriate sodium replacement for the urinary electrolyte losses. The commonly described 'sodium paradox' (Wilson et al.) of a falling plasma sodium whilst the patient is kept in sodium and water balance may be observed if insufficient sodium is given to cover also the potassium losses, sodium and potassium being osmotically equivalent (Wynn and Houghton, in the press). As the total urinary $(\mathrm{Na}+\mathrm{K})$ losses usually amount to 60 to $100 \mathrm{mEq}$. per 24 hours, $750 \mathrm{ml}$. of normal saline per 24 hours generally proves sufficient, with the additional water supplied as dextrose solutions. Potassium can be added to infusion solutions to the extent of 25 to $50 \mathrm{mEq}$. per 24 hours when large losses are occurring, but this is safe only when the patient is passing more than $800 \mathrm{ml}$. of urine in 24 hours. The accompanying table lists the average composition of secretions from the gastrointestinal tract and replacement of losses should be arranged appropriately, using normal or halfnormal sodium chloride solutions with potassium chloride supplements. These figures are intended only as a guide, for the exact composition varies in individuals and direct analysis of these fluids should be performed whenever possible.

\section{Correction of Complications}

The first essential is, of course, the establishment of a correct clinical and biochemical diagnosis, for the aim in treatment must be the correction of the condition which has led to the clinical and biochemical state observed in the patient, and not just an attempt to 'put the figures right.' With this in view it is clearly vital that accurate fluid balance records should be kept for any patient subjected to a major surgical procedure, and also that whenever possible the patient should be weighed before operation. A detailed clinical examination and reference to the fluid balance charts will generally lead to the correct diagnosis, although in some cases this is not possible until the results of blood and urine analyses are available. In the absence of recent tissue wasting the presence in the adult of signs of loss of skin elasticity represents the deficiency of not less than 2 litres of extracellular fluid. Estimations of the plasma $\mathrm{Na}, \mathrm{K}, \mathrm{Cl}, \mathrm{HCO}_{3}$ and urea should be done whenever possible, and in the case of a depleted patient will give information as to the relative deficiency of water and sodium; e.g. if the plasma sodium is normal or low and the urea raised, sodium depletion is present, and a falling bicarbonate concentration represents a developing metabolic acidosis. On the other hand, a high bicarbonate and low chloride in this patient would suggest a metabolic alkalosis from loss of acid gastric secretions or from potassium depletion.

Let us consider first a patient who has oliguria, signs of loss of skin elasticity, dry mucous membranes and hypotension, with a plasma sodium of $126 \mathrm{mEq}$. per litre, potassium $5.5 \mathrm{mEq}$. per litre, chloride $90 \mathrm{mEq}$. per litre and bicarbonate $20 \mathrm{mEq}$. per litre. The clinical findings indicate a loss of extracellular fluid, and the low plasma sodium shows that the electrolyte loss is 
relatively greater than that of water. The lowered bicarbonate and relatively greater reduction in analysed anions compared with cations suggests a metabolic acidosis. There are two aspects to the fluid replacement in this case: first, the bulk replacement of the missing extracellular fluid with an isotonic sodium solution; and secondly, the provision of additional sodium salts in appropriate amounts to elevate the concentration in the existing body fluids. However, as during the period of intravenous correction therapy the patient will need water to cover the obligatory losses, this additional sodium can usually be supplied in the form of an isotonic solution if the infusion is spread over more than 48 hours. In the normal course of events 2 litres of normal saline may be given fairly rapidly to restore extracellular fluid volume, and the clinical signs of depletion should regress. A third, or even a fourth, litre may be given if clinically indicated whilst therapy is in progress. In order to correct the existing low sodium concentrations further calculations are needed, as it is necessary to ascertain the amount of sodium that must be added to raise the concentrations in all the body fluid by the desired amount. If calculated on the basis of the extracellular fluid volume the infusion fails to produce the expected rise in plasma sodium because increased electrolyte concentrations in the extracellular compartment result in the shift of water from the cells and equilibration as if the sodium were distributed in the entire body water. Let us suppose that our patient, a male, weighed $70 \mathrm{~kg}$. before operation and his total body fluid volume was therefore about 42 litres (6o per cent. of body weight), and that it is desired to raise his overall plasma sodium concentration to $140 \mathrm{mEq}$. per litre. Sufficient sodium must be infused to raise the existing 40 litres of body fluid by $(140-126=14) \mathrm{mEq}$. per litre, and, therefore $(40 \times 14=560) \mathrm{mEq}$. of sodium are necessary. This amount could be given as a hypertonic solution over a period of, say, 24 hours; or, better, could be infused slowly as an isotonic solution over a period of some 48 hours. It is advisable to repeat the blood analyses 24 hours after commencement of intravenous therapy, for in this way errors due to estimation of, say, the initial total body water will not incur clinical risks. It is also of vital importance to watch the state of the circulation, especially in elderly patients in whom the dangers of pulmonary oedema are great. It is generally wise to lengthen the time period over which replacement is carried out in such patients. A further advantage of a slower infusion is that it allows an opportunity to observe the recovery of renal function and if a serious renal shutdown such as in tubular necrosis has occurred adjust- ments to fluid prescriptions can be made before the patient is filled with electrolytes which he will $\frac{2}{3}$ be unable to excrete. Conservative treatment $\stackrel{\$}{\circ}$ can thus be commenced early.

Similar principles govern the calculations* for the correction of all disorders, but one further $\stackrel{5}{?}$ example, namely, acute water intoxication, may? be mentioned. Let us consider a female patient $\frac{\bar{\sigma}}{\overline{0}}$ who has had an elective partial gastrectomy and $\frac{\bar{\sigma}}{\sigma}$ who, in the first 48 hours after operation, has $\stackrel{\unrhd}{\varrho}$ received a sufficiently large excess of water (by intravenous or rectal routes) to induce drowsiness $\rightarrow$ and other signs of water intoxication. Let us, $\stackrel{-}{-}$ furthermore, suppose that she is found to have a $\vec{\omega}$ plasma sodium of $118 \mathrm{mEq}$. per litre and that her $\stackrel{\rho}{\circ}$ pre-operative body weight was $60 \mathrm{~kg}$. As the 8 female generally has a slightly greater proportion 3 of body fat compared with a male of the same $\underset{\omega}{\omega}$ weight we will assume that the initial total body $\omega_{\infty}$ water was approximately 50 per cent. of the body weight, i.e. in our patient the total body water $o$ was approximately 30 litres. If the patient's

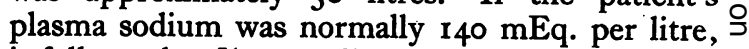
it follows that $[(140-1 \mathrm{r} 8) \times 30] \mathrm{mEq}$. or $660 \mathrm{mEq}$. of sodium have been transferred into the additional water, the volume of which was approximately $(660 \div 118=5.6)$ litres. The amount of sodium chloride necessary to restore the initia sodium concentration of $140 \mathrm{mEq}$. per litre to the expanded total body water (35.6 litres) is thus of $[($ I $40-1 \mathrm{I} 8) \times 35.6]=783 \mathrm{mEq}$. , and it must obv든 ously be in hypertonic solution, say, approximatefy 3 to 5 per cent. $w / v$. The infusion should be given into a large vein over a period of not less than six hours, and the clinical improvement is usually quite dramatic. As a general rule it is wise to give only about two-thirds of the calculated amounts of sodium in the first 24 hours and to wait for a simultaneous diuresis.

In situations where the plasma is hypertonic with respect to sodium the simplest method is to calculate the total excess of sodium salts present and thus the volume of water necessary to dilute them down to normal plasma concentrations.

\section{Summary and Conclusions}

The post-operative period carries certain special $\frac{O}{D}$ hazards in relation to fluid and electrolyte balance, and disorders of body fluid volume, osmolarity and acid-base balance may occur.

The fluid and electrolyte requirements of a $N$ patient post-operatively are dictated by the meta- N bolic response, and the general principles have been considered. It is important, however, too remember the influence of co-existing cardio- $\mathbb{D}$

*The hasic formulae have been simplified in this
account. 
respiratory, renal and other diseases in modifying the response of the patient, and newer surgical techniques involving the use of relaxant drugs and hypothermia bring their own peculiar problems.

Awareness of possible fluid complications is the surest way of preventing them, and care taken in pre-operative assessment and treatment is well repaid in the smooth post-operative course. When fluid and electrolyte losses have occurred, accurate quantitative assessment of the biochemical derangement must be the prelude to plans for corrective therapy.

In this way the surgeon building his prescriptions on sound clinical, chemical and mathe- matical foundations can face the metabolic hazards of surgery with confidence, and avoid fluid complications in his patients.

Average Composition of Secretions from The Gastro-intestinal Tract

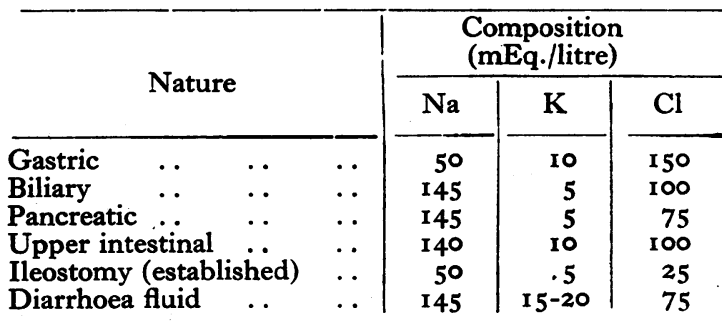

BONGIOVANNI, A. M., and EISENMENGER, W. J. (I95I), 7. clin. Endocr., $11,152$.

BORST, J. G. G. (1948), Lancet, i, 824.

BORST, J. G. G. (I048), Acta. med. scand. 1 30 , Suppl. 207.

BULL, G. M., JOEKES, A. M., and LOWE, K. G. (I949), Lancet,

BUNKER, J. P., STETSON, J. B., COE, R. C., GRILLO, H. C., and MURPHY, A. J. (1955), 甹. Amer. med. Ass., 157, 16, 1361. COOKE R. E SEG R W. E. CHEEK, D. B., CÓLVILLE,

F. E., and DARROW, D. C. (1952), F. clin. Invest., 31, 798.

CUTHBERTSON, D. P. (1930), Biochem. F., 24, 1244.

CUTHBERTSON, D. P. (1936), Brit. F. Surg., 23, 505.

DARROW, D. C. (1946), f. Pediat., 28, 515.

DARROW, D. C., SCHWARTZ, R., IANUCCI, J. F., and COLVILLE, F. (1948), 7 . clin. Invest., 27, x98.

DARROW, D. C., and PRATT, E. L. (r950), f. Amer. med. Ass., I43, 365 and 432.

GOLDMAN, R., and BASSETT, S. H. (1952), $\mathcal{F}$. clin. Invest., 29, 973.

\section{BLIOGRAPHY}

HALL,C.A., FRAME, B., and DRILL, V. A. (1949), Endocrinology $44,76$.

MOORE, F. D., and BALL, M. R. (I952), "The Metabolic Response to Surgery' Springfield, Illinois, C. C. Thomas.

PARSONS, F. M., PYRAH, L. N., POWELL, F. J. N., REED, G. W., and SPIERS, F. W. (I952), Brit. F. Urol., 24, 317. PETERS, J. P. (1948), Nero Engl. F. Med., 239, 353.

SIMS, J. L. (1950), Y. Lab. clin. Med., 36,990.

STREETEN, D. H. P., and WARD-MCQUAID, J. N. (1952), Brit. med. Ұ. ii, 587 .

DE TAKATS, G. (193I), Amer. F. Surg., II, 39.

VERNEY, E. B. (1947), Proc. roy. Soc. B, 135, 25 . STEWART, C. P. (1950), Lancet, i, 533;' Ibid., ii, 135 .

WILKINSON, A. W. (1954), Postgrad. med. '̛., 30, 405 .

WILSON, G., BROOKS, L., and MOORE, F. (1953), f. clin Invest., 32, 612 .

WYNN, V. (1954), Lancet, il, 575.

WYNN, V. (1955), Clin. Sci., 14, 669.

\title{
THYROID DISEASE
}

(Postgraduate Medical Fournal, fuly 1957)

Price: 3s. 9d., post free

DIAGNOSTIC PROCEDURES IN THYROID DISEASE

Russell Fraser, M.D., F.R.C.P., D.P.M.

THE PLACE OF RADIOACTIVE IODINE IN THE TREATMENT OF THYROID DISEASE

E. E. Pochin, M.D., F.R.C.P.

\section{ANTITHYROID DRUGS}

James Crooks, M.B., M.R.C.P. (Lond. and Ed.), F.R.F.P.S.G.

SUBACUTE THYROIDITIS

Selwyn Taylor, M.Ch., F.R.C.S.
RECENT WORK ON THYROID HORMONES

J. H. Wilkinson, B.Sc., Ph.D., F.R.I.C.

SOME UNUSUAL MANIFESTATIONS OF THYROID DISEASE

W. R. Trotter, D.M., M.R.C.P.

CARCINOMA OF THE THYROID

John E. Piercy, F.R.C.S., F.R.C.S.E.

\section{LYMPHOID GOITRES}

T. Levitt, M.A., F.R.C.S.Eng., F.R.C.S.Ed., F.R.C.S.I

Published by

\section{THE FELLOWSHIP OF POSTGRADUATE MEDICINE}

\author{
60, Portland Place, London, W.1
}

